\title{
Government Policy with Time Inconsistent Voters
}

\author{
By Alberto Bisin, Alessandro Lizzeri, And Leeat Yariv*
}

\begin{abstract}
Behavioral economics presents a "paternalistic" rationale for benevolent government intervention. This paper presents a model of public debt where voters have self-control problems and attempt to commit using illiquid assets. In equilibrium, government accumulates debt to respond to individuals' desire to undo their commitments, which leads individuals to rebalance their portfolio, in turn feeding into a demand for further debt accumulation. As a consequence, (i) large (and distortionary) government debt accumulation occurs, and (ii) banning illiquid assets could improve individuals' welfare. These results offer a new rationale for balanced budget rules in constitutions to restrain governments' responses to voters' self-control problems.(JEL D2, D72, D78, H62, H63)
\end{abstract}

This paper presents an analysis of how economic policy responds to the political demands of agents with self-control problems. The main result is that collective action may generate an amplification of individual self-control problems leading to excessive government debt. The analysis also provides some cautionary discussion of commonly advocated policies (such as facilitating investment in illiquid assets) in a world where government debt responds to the portfolios of private individuals.

An important and influential approach to government policy has grown out of the field of behavioral economics. A number of contributors to this area argue that some form of government policy interventions can be justified by "paternalistic attitudes" even in cases outside the realm of the textbook approach to public policy, i.e., even absent externalities, public goods, and asymmetric information. ${ }^{1}$ Within behavioral economics, a substantial body of work discusses self-control problems and their consequences within a consumption-savings environment. Some argue that there are inefficiently low savings when individuals are left to their own devices (e.g., Camerer, Loewenstein, and Rabin 2003; Hurst 2003; and Madrian 2012). These insights have been used for justifying paternalistic interventions by governments aimed at

\footnotetext{
* Bisin: Department of Economics, New York University, 19 West 4th Street, New York, NY 10012 (e-mail: alberto.bisin@nyu.edu); Lizzeri: Department of Economics, New York University, 19 West 4th Street, New York, NY 10012 (e-mail: alessandro.lizzeri@nyu.edu); Yariv: Division of the Humanities and Social Sciences, Caltech, MC 228-77, Pasadena, CA 91125 (e-mail: lyariv@ hss.caltech.edu). We thank Daron Acemoglu, Guido Lorenzoni, Wolfgang Pesendorfer, Nikita Roketskiy, Bernardo Silveira, and Michael Ting for very helpful discussions and feedback. We gratefully acknowledge financial support from the National Science Foundation and the Gordon and Betty Moore Foundation (through grant 1158). Bisin wishes to acknowledge the support of the Ministry of Education and Science of the Russian Federation, grant 14.U04.31.0002, administered through the NES CSDSI.

${ }^{\dagger}$ Go to http://dx.doi.org/10.1257/aer.20131306 to visit the article page for additional materials and author disclosure statement(s).

${ }^{1}$ See, for instance, Camerer, Loewenstein, and Rabin (2003) and Thaler and Sunstein (2009).
} 
helping individuals save, such as encouraging accumulation of illiquid assets, various forms of forced savings plans, as well as public pension systems (see Camerer et al. 2003, Laibson 1998, Thaler and Sunstein 2003, and the literature that followed). A related set of recent papers argues that individuals who suffer from self-control problems may accumulate excessive private debt, for instance, in the form of large credit card balances (see Shui and Ausubel 2005; Gottlieb 2008; and Heidhues and Köszegi 2010). These papers provide policy recommendations that attempt to rein in excessive debt by placing constraints on the actions of private intermediaries such as credit card companies (e.g., banning teaser rates, see Sunstein 2006).

This literature implicitly assumes a model of policy making that relies on a benevolent government. Of course, the assumption of a benevolent government is just a benchmark: a richer understanding of government intervention requires a more nuanced model of its decision-making process. The political economy and public choice literature has investigated many of the more traditional realms of government intervention such as the provision of public goods, but there is little work related to how political incentives affect outcomes in environments with "behavioral" voters. Our goal in this paper is to understand how political incentives may interact with voters' self-control problems in a consumption-savings environment, where government may accumulate public debt. In general, in environments where voters suffer from behavioral biases, one may worry that politicians seeking election may exploit or indulge voters' behavioral distortions. In order to understand the impacts of government policy on capital accumulation, it is important to inspect how political incentives for debt are affected by voters' self-control problems.

To study these issues, we embed politically determined government transfers in a stylized consumption-savings problem. We show that large (and distortionary) government debt accumulation occurs in equilibrium. Our model provides new justifications for restrictions on government debt accumulation. We also show that some of the policies that have been advocated in the prior literature (such as facilitating instruments of commitment like illiquid assets) may backfire in a world where government policy is endogenous.

We study a simple three period model. ${ }^{2}$ We endow agents with ample commitment options by means of access to illiquid assets. Agents use illiquid assets to constrain their future selves' consumption plans. The environment is designed to ensure that, absent government intervention, agents can guarantee their commitment path of consumption. ${ }^{3}$ We introduce government intervention by allowing office-seeking candidates to offer deficit-financed transfers to voters, subject to a maximal debt limit. When agents suffer from self control, government will accumulate debt to respond to the individuals' desire to undo their commitments. But the presence of government debt gives sophisticated agents a motive to rebalance their portfolio to reestablish their commitment consumption sequence. This feeds a subsequent demand for further debt accumulation. We show that for moderate debt limits, in equilibrium, candidates choose the maximal debt, but voters are able to undo this by rebalancing their portfolios ex ante: a modified Ricardian equivalence result. When debt limits are high, however, a large government debt undermines individuals' ability to commit.

\footnotetext{
${ }^{2}$ In online Appendix, Section B, we extend the analysis to an arbitrary (finite) number of periods.

${ }^{3}$ An interpretation, of course, is that government policy has facilitated the availability of such illiquid assets.
} 
This force is present even with distortions from debt accumulation (e.g., distortionary taxes) as long as the marginal distortions are not too high relative to the present bias of the decisive voter. Equilibrium debt can then still be high, leading to high total distortions. We also show that this vicious cycle is not present in the context of an individual being offered liquid assets to undo her prior commitments (as, for instance, in Gottlieb 2008). In private credit arrangements, an individual understands that her first period choices affect her own choices in the second period. In contrast, this link between individual choices in the first period and collective choices in the second is absent in the case of government debt. Because debt is determined via collective choice in the future, individual portfolio decisions in prior periods have no impact on subsequent debt. The analysis therefore offers a new rationale for balanced budget rules in constitutions.

We also show that, under fairly mild conditions, welfare corresponding to all selves is highest if agents do not have access to illiquid assets and hence do not have the ability to commit to later consumption. This is because, in this scenario, no government debt is accumulated in equilibrium. Of course, for any fixed level of government debt, first-period selves of these agents are worse off because of their inability to commit. The inefficiency arises as a consequence of the feedback between the demand for illiquid assets in the first period and the demand for debt-financed transfers in the second period. This result provides a different interpretation of the policy recommendations from prior literature that suggest a beneficial effect of policies facilitating savings commitments.

Our paper is also a contribution to the political economy literature on government debt (see below for references). This literature is motivated by the fact that it is very difficult to justify existing large debt levels in most democracies with any efficiency criterion. A variety of forms of political distortions have been invoked to attempt to explain government debt. Our model is qualitatively very different from those existing in the literature. More importantly, our paper delivers a novel link between the financial structure of the economy, as represented by the availability of illiquid assets, as well as short-term private debt such as credit cards, and the size of government debt.

Although we model the political process as the outcome of elections with office-motivated candidates, the key forces in the model will be present more generally in models where government is responsive to voters' immediate desires. For instance, an alternative interpretation that leads to the same results is that the government is benevolent but lacks commitment and cannot control individual agents' portfolio decisions.

\section{Related Literature}

Some authors (Benjamin and Laibson 2003; Caplan 2007; Glaeser 2006; Rizzo and Whitman 2009a, b) have informally made the point that when government is not run by a benevolent social planner but by politicians influenced by voting decisions, it is not clear that government intervention is beneficial. In fact, Glaeser and Caplan explicitly make the case that, if voters are boundedly rational, then the case for limited government may be even stronger than in standard models. None of these papers considers time inconsistent agents. Bendor et al. (2011) present models assuming 
aspiration-based learning to examine a wide variety of political phenomena. Hwang and Mollerstrom (2012) study political reforms with time inconsistent voters and show that gradualism emerges in equilibrium as a consequence of time inconsistency. They also show that election of a patient agenda setter can arise in equilibrium. Lizzeri and Yariv (2014) also study an environment with voters suffering from self-control problems and discuss the desirability of various forms of collective action. The paper distinguishes interventions at a "commitment stage" from interventions at a "consumption stage." They show that, if only commitment decisions are centralized, commitment investment is more moderate than if all decisions are centralized. Commitment investment is minimal when only consumption is centralized. First-period welfare is highest under either full centralization or laissez faire, depending on the distribution of the degree of present bias in the population. The model presented by Lizzeri and Yariv is not well suited for studying the interaction between public debt and private commitments that is the focus of the present paper. ${ }^{4}$

There are several papers that explore optimal disciplining of governments that are themselves prone to self-control problems (without explicitly linking their preferences to the electoral process or the underlying preferences of the electorate). Amador, Werning, and Angeletos (2006) characterize the optimal budget set, balancing commitment and flexibility, for decision-makers who are susceptible to temptation and face a consumption-savings problem in which independent taste shocks are experienced over time. Halac and Yared (2014) use this setting as a spring-board to study the optimal levels of discretion in policy making. They depart from Amador, Werning, and Angeletos (2006) by allowing for persistent taste shocks and interpret decision-makers as governments with a present bias toward public spending. Piguillem and Riboni (2013) also consider politicians who have a present bias for spending and bargain dynamically. They show that disagreement leads to more persistent policies and attenuation of the immediate desire of bargaining proposers to over-spend.

Our paper is also related to the literature on the political economy of government debt. Some of that literature explains debt as the outcome of a struggle between different groups in the population who want to gain more control over resources. The reason debt is accumulated is that the group that is in power today may not be in power tomorrow and debt is a way to take advantage of this temporary power. For instance, Cukierman and Meltzer (1989) and Song, Storesletten, and Zilibotti (2012) argue that debt is then a tool to redistribute resources across generations. Persson and Svensson (1989); Alesina and Tabellini (1990); and Alesina and Tabellini (1990) argue that debt is a way to tie the hands of future governments that have different preferences from the current one. In Alesina and Tabellini (1990) voters choose the composition of public spending in an environment where the median voter theorem applies. If the median voter remains the same in both periods the equilibrium involves budget balance. If the median voter tomorrow has different preferences, the current median voter may choose to run a budget debt to take advantage of his temporary power and tie the hands of the future government. The equilibrium may also involve a budget surplus because there is an "insurance" component that links

\footnotetext{
${ }^{4}$ Ortoleva and Snowberg (2015) look at the potential effects of over-confidence on electoral outcomes.
} 
the two periods: a surplus tends to equalize the median voter's utility in the two periods. Alesina and Tabellini give conditions such that debt will be incurred and show that increased polarization leads to larger debt levels. Battaglini and Coate (2008) present a dynamic model of taxation and debt, where a rich policy space is considered within a legislative bargaining environment. Velasco (1996) suggests a model where government resources are a "common property" out of which interest groups can finance their own consumption. Debt arises in his model as a consequence of a dynamic "common pools" problem. Lizzeri (1999) presents a model of debt as a tool for redistributive politics. 5

In all these models voters are time consistent. Krusell, Kurusçu, and Smith (2002, 2010) examine government policy for agents who suffer self-control problems. Krusell, Kurusçu, and Smith (2002) consider a neoclassical growth model with quasi-hyperbolic consumers. They show that, when government is benevolent but cannot commit, decentralized allocations are Pareto superior. This is due to a general equilibrium effect of savings that exacerbates an under-saving problem. Bénabou and Tirole (2006) discuss how endogenously biased beliefs that are chosen by individuals for self-motivation can generate a belief in a just (or unjust) world and ultimately affect redistributive politics.

\section{Model}

\section{A. Economy}

Preferences.-We first consider a particularly simple three period model to highlight the basic idea in a particularly stark fashion.

There is a measure 1 of voters who live for three periods. To make things particularly simple, assume that in period 1 voters only make savings and portfolio decisions but do not receive any utility from consumption. ${ }^{6}$ There is wealth $k$ from which to finance consumption over periods 2 and 3. No endowment is available in the other two periods..$^{7}$ Following Laibson (1997), preferences over a consumption sequence $c_{2}, c_{3}$ are given by

$$
\begin{aligned}
U_{1}\left(c_{2}, c_{3}\right) & =\beta\left[\delta u\left(c_{2}\right)+\delta^{2} u\left(c_{3}\right)\right], \\
U_{2}\left(c_{2}, c_{3}\right) & =u\left(c_{2}\right)+\beta \delta u\left(c_{3}\right), \\
U\left(c_{3}\right) & =u\left(c_{3}\right),
\end{aligned}
$$

\footnotetext{
${ }^{5}$ Tabellini (1991) also illustrates how debt and social security differ as distributional instruments in an overlapping generations environment.

${ }^{6}$ The analysis with homogeneous agents is almost identical when there is consumption in period 1 as well. New forces emerge, and results are more subtle, in the case of heterogeneous agents. This case is discussed in more detail in online Appendix, Section D.

${ }^{7}$ It is easy to accommodate positive endowments in all periods. It is also possible, but more complicated, to allow for heterogeneity in wealth. What is important is that agents can make decisions that affect the future path of consumption. This can happen either because there is a substantial fraction of the population who desires to save in period 1. Alternatively, we could assume that consumers are able to privately borrow against future endowments in period 1 and then wish to commit to a path of consumption.
} 
where $u$ is a continuous and strictly concave utility function. We also assume that the utility function is three times continuously differentiable. We assume that agents are identical. We discuss the effects of heterogeneity in online Appendix, Section D. For expositional simplicity, and since our main focus is on the impacts of time inconsistency, we assume that $\delta=1$.

It is well-known that agents with quasi-hyperbolic preferences suffer from time inconsistency, and therefore exhibit demand for commitment. We assume that agents are sophisticated: they are fully aware of their self-control problems. ${ }^{8}$ Let $c_{2}^{*}$ and $c_{3}^{*}$ denote the optimal consumption sequence with commitment in period 1. Namely, $c_{2}^{*}$ and $c_{3}^{*}$ maximize $U_{1}\left(c_{2}, c_{3}\right)$ subject to $c_{2}+c_{3} \leq k$. Let $c_{2}^{U}$ and $c_{3}^{U}$ denote the optimal consumption sequence without commitment. Absent commitment, period 2 consumption $c_{2}$ maximizes $U_{2}\left(c_{2}, c_{3}\right)$ subject to $c_{2}+c_{3} \leq k$.

To highlight the demand for commitment, consider any $\beta<1$, and the commitment consumption sequence $c_{2}^{*}, c_{3}^{*}$. This sequence must satisfy $u^{\prime}\left(c_{2}^{*}\right)=u^{\prime}\left(c_{3}^{*}\right)$, which implies $c_{2}^{*}=c_{3}^{*}$. Furthermore, $u^{\prime}\left(c_{2}^{*}\right)>\beta u^{\prime}\left(c_{3}^{*}\right)$ and thus, in period 2, agents would like to transfer resources from the third period to the second to obtain a consumption that is strictly higher than $c_{2}^{*}$.

Indeed, absent commitment, $c_{3}^{U}=k-c_{2}^{U}$; and $c_{2}^{U}$ satisfies $u^{\prime}\left(c_{2}^{U}\right)=\beta u^{\prime}\left(c_{3}^{U}\right)$. It is then straightforward to conclude the following:

\section{LEMMA 1: Commitment leads to lower second period consumption: $c_{2}^{*}<c_{2}^{U}$.}

Financial Structure and Commitment.-We assume that in period 1 voters can choose to invest their wealth $k$ in liquid or illiquid assets. Assume all liquid and illiquid assets have the same exogenous interest rate of zero. ${ }^{9}$ Illiquid assets are two-period securities that cannot be sold in period 2. Liquid assets are one-period securities. Absent government intervention in period 2, by appropriate choice of the mix of liquid and illiquid assets, a voter can commit to any desired consumption stream for periods 2 and 3 . We denote savings in one period assets, in periods 1 and 2 , by $s_{1,2}$ and $s_{2,3}$ respectively, and savings in illiquid assets by $s_{1,3}$.

The interplay between agents' desire to commit in period 1 and government actions in the subsequent period is a key effect in our model. Allowing for imperfect commitment generates some interesting additional effects but the major forces are similar. We will return later to the consequences of allowing for differences in returns of liquid and illiquid assets, as well as of allowing the government to subsidize illiquid assets (for instance, as in the case of retirement plans).

\footnotetext{
${ }^{8}$ The qualitative nature of our results would not change if agents had only partial awareness of their self-control problems, i.e., if agents were partially sophisticated $(\beta<\hat{\beta}<1$ in the terminology of O'Donoghue and Rabin 1999). We could also allow a fraction of the agents to be fully naïve. The analysis would also remain qualitatively similar were we to consider a setting in which individuals exhibited temptation costs, rather than quasi-hyperbolic preferences, à la Gul and Pesendorfer $(2001,2004)$. For a detailed description, see online Appendix, Section C.

${ }^{9}$ We discuss a more general structure of returns in Section III.
} 


\section{B. Polity}

We now introduce a government that takes actions in periods 2 and $3 .{ }^{10}$ We model government actions as arising out of electoral concerns. ${ }^{11}$ Specifically, there are two candidates running for office. Candidates are office motivated: they receive some positive benefit from electoral victory and hence choose electoral platforms to maximize the probability of winning.

It will soon be clear that candidates' time preferences play no role, and that they need not be the same candidates in the two periods. There are simple majoritarian elections in periods 2 and 3. In period 2, each candidate offers a platform given by $(y, t)$ where $y$ is a per capita transfer and $t$ is a lump-sum tax. Let $d=y-t$ denote per capita government debt in period 2 . When taxes are non-distortionary, all that matters is debt. If taxes are distortionary, there is no reason to have positive contemporaneous taxes in this model. Thus, from now on, we assume that transfers are debt financed so we equate debt and transfers. We assume that, in each period, voters use strategies that are not weakly dominated. In particular, each agent votes for the candidate that offers the platform that they like most. As a tie-breaking rule, we assume that whenever individuals are indifferent between the two candidates, they vote for either with equal probability. ${ }^{12}$

In what follows, we first consider a benchmark in which debt is non-distortionary and then move on to the case of distortionary debt. We assume debt is financed by foreign lenders at zero interest rate (tantamount to assuming a small open economy), ${ }^{13}$ to be repaid by third-period revenues raised by lump-sum taxes. We wish to study the effects of constitutionally imposed borrowing limits on the government; let $\bar{d}$ denote the per capita value of this limit.

In period 1 an agent who predicts equilibrium per capita debt levels of $d$ and period 2 savings $s_{23}$, chooses period 1 savings intended for period 2 , denoted by $s_{12}$ and for period 3 , denoted by $s_{13}$, to solve

$$
\begin{aligned}
& \max _{s_{12}, s_{13}} \beta\left[u\left(s_{12}+d-s_{23}\right)+u\left(s_{13}+s_{23}-d\right)\right] \\
& \text { s.t. } s_{12}+s_{13} \leq k .
\end{aligned}
$$

Note that, since there is a continuum of voters, this agent takes as given the second period debt when making first-period choices. 14

\footnotetext{
${ }^{10}$ In online Appendix, Section A, we consider the effects of first period elections.

${ }^{11}$ This is analogous to a social planner without commitment who cannot control agents' portfolio decisions.

${ }^{12}$ This is akin to assuming that agents have lexicographic preferences that: (i) respond to policy first, and upon indifference, to the identity of the candidate; and (ii) are uniformly distributed with respect to the preferred candidate.

${ }^{13}$ The main forces present in our model would remain even if we considered interest rate determination in a closed economy. General equilibrium effects are subtle, however, when agents are quasi-hyperbolic (see Krusell, Kuruşçu, and Smith 2002).

${ }^{14}$ The belief by agents that their individual savings behavior does not affect second-period debt is clearly correct for the case assumed here with a continuum of voters. With a finite electorate it would be possible to construct different equilibria but these would not be robust to adding some forms of noise in the second period (e.g., noise in second-period turnout). What we effectively require is that in the first period each agent believes that there is a negligible probability that he is the pivotal voter in the second period.
} 
In period 2 a voter with preference parameter $\beta$ chooses savings $s_{23}$ to solve

$$
\max _{s_{23}} u\left(s_{12}+d-s_{23}\right)+\beta u\left(s_{13}+s_{23}-d\right),
$$

taking as given $d$ and $s_{12}, s_{13}$ that satisfy $s_{12}+s_{13} \leq k$ and solve the period 1 problem. The resulting optimal consumption sequence is denoted $c_{2}(d), c_{3}(d)$. Suppose that candidate $A$ chooses a debt $d_{A}$ and candidate $B$ chooses debt $d_{B}$. Then the voter votes for $A$ in period 2 whenever $u\left(c_{2}\left(d_{A}\right)\right)+\beta u\left(c_{3}\left(d_{A}\right)\right)>u\left(c_{2}\left(d_{B}\right)\right)+\beta u\left(c_{3}\left(d_{B}\right)\right)$.

\section{Time Inconsistency in the Context of Political Decisions}

Quasi-hyperbolic discounting links self-control problems with a bias in preferences for the present as opposed to all subsequent periods. The definition of period length is then crucial for the scope of self-control problems and for evaluating potential policies that attempt to limit their impact. Experimental work assessing time discounting is almost necessarily bound to focus on comparisons between immediate rewards and ones that are delayed, usually by only a few weeks (see Frederick, Loewenstein, and O'Donoghue 2002 and, for instance, Augenblick, Niederle, and Sprenger 2013 for more recent references). It could be argued then that voting would not be subject to much of a self-control problem. In this respect, we note that while in our model we literally only allow voters' preferences to affect policies through elections, there are many ways in which short-term popular support may affect government behavior between elections, and therefore at higher frequencies than the electoral cycle. The simplest link between policies and "current-self" preferences is an extreme case in which a government readily reacts to contemporaneous opinion polls. ${ }^{15}$ Our model directly covers this case when appropriately extended to a larger number of periods (see the discussion in online Appendix, Section B, for an analysis of such a model): it is easy to see that, in our context, a model where the government responds to (accurate) polls is analogous to a model with a larger number of periods in which there are elections in all periods. Moreover, (and more informally), the strength of the electorate's preferences can be felt by an incumbent government through channels other than elections, e.g., through lobbying and fund-raising events.

Furthermore, our view is that quasi-hyperbolic preferences are a convenient way to model self-control problems, and the interpretation of immediacy of gratification is just an unnecessarily narrow and literal interpretation. Self-control problems naturally manifest themselves at relatively long frequencies like electoral cycle frequencies. Our view is also supported by studies that find evidence for self-control problems even at fairly long horizons. There are a number of survey-based studies in which agents face intertemporal trade-offs at long horizons (several years). These studies report evidence in favor of hyperbolic discounting. Chesson and Viscusi (2000), for instance, document discount rates that decrease over time, as in hyperbolic discounting models, for business managers facing a choice between a payment option offering a known payoff time and one offering a gamble over the timing of the

\footnotetext{
${ }^{15}$ For a survey discussing the policy responsiveness to public opinion, see Erikson (2013).
} 
award, both delayed by several years depending on the treatment. ${ }^{16}$ Further evidence has elicited intertemporal preferences with respect to non-monetary payoffs. For instance, Viscusi and Huber (2006) surveyed approximately 1,000 subjects regarding their preferences over potential (costly) water improvement policies that were to start in different years. The subjects' responses were consistent with a quasi-hyperbolic model of time preferences, even when controlling for risk. Furthermore, survey studies of intertemporal preferences over health outcomes provide evidence in favor of hyperbolic discounting, a generalization of the quasi-hyperbolic model with very similar behavioral implications. In van der Pol and Cairns (2002), for instance, respondents are offered the opportunity for a spell of ill health 2 or 3 years into the future to be delayed (by 2-5 years up to 10-13 years, depending on the experimental treatment) as a result of a medical intervention. Subjects are then asked to report a maximum number of days of future ill health, after the delay, at which it would still be worthwhile to receive this treatment (see also Bleichrodt and Johannesson 2001; Chapman 1996; and van der Pol and Cairns 2001, 2011). ${ }^{17}$

Indeed, quasi-hyperbolic models of intertemporal preferences have proved useful in the study of many decision problems, not just ones occurring at high frequencies. Laibson, Repetto, and Tobacman (2007) use data on retirement wealth accumulation, credit card borrowing, and consumption-income comovements to identify discount functions. Their preferred specification yields an estimate for the quasi-hyperbolic model implying a sizable present bias even though decisions are assumed to be taken yearly. Karp and Tsur (2011) study a calibrated model of the probability of a climate change catastrophe induced by the accumulation of greenhouse gases when agents have a tendency to procrastinate putting in place policies to avert such a catastrophe due to hyperbolic discounting; see also Karp (2005); Fujii and Karp (2008); Nordhaus (2009); Nordhaus and Boyer (2003); and Mastrandrea and Schneider (2010). Similarly, hyperbolic discounting plays a relevant role in studies of environments characterized by exhaustible resources: see Rowse (2006) for an application to world oil resources and Settle and Shogren (2006) for an application to fisheries. 18

Finally, there is an alternative way to interpret quasi-hyperbolic discounting as the result of a decision-maker aggregating preferences of individuals with heterogeneous discount factors within groups, or facing uncertainty over his/her own future discount factor. This interpretation does not require any "psychological" tastes for immediate gratification. Individuals' uncertainty over their future discount factor could be due to uncertainty over their future income stream and consequent accessible interest rates, unforeseen inflation rates, etc. But, most importantly, if we interpret our analysis as regarding political influence on government policy, then individuals could represent political pressure or interest groups whose political actions aggregate heterogeneous trade-offs between the present and the future. This is the interpretation given to hyperbolic discounting in the study of social preferences over

\footnotetext{
${ }^{16}$ See also Chapman (1996), Cairns and van der Pol (1997), and references therein.

${ }^{17}$ Interestingly, hyperbolic discounting is documented also in related survey studies eliciting intertemporal social preferences; e.g., when respondents trade off saving lives at different future times; see Cairns and van der Pol (1997) and Johannesson and Johansson (1996).

${ }^{18}$ We should also note the extensive body of literature using the hyperbolic discounting model as a framework to discuss (and provide a justification for) an array of policies with long-run effects, most notably regarding retirement savings ( see our literature review above).
} 
climate change policies in Goulder and Williams (2012) and more generally to the related "gamma discounting" cost-benefit analyses in Weitzman (2001). ${ }^{19}$

\section{Equilibrium Debt and its Consequences}

We now characterize equilibrium in the world with time-inconsistent agents for all possible constraints on debt accumulation. We first discuss the benchmark case of zero distortions from debt and taxes. This case is particularly simple. However, to highlight the richness of the environment, we later move on to consider the case of distortionary debt (or taxes).

\section{A. Equilibrium without Distortions}

The following result characterizes equilibria for all possible debt limits. There is always an incentive for politicians to promise debt-financed transfers, but the consequences of such debt on agents' equilibrium consumption depend on how tight debt limits are.

PROPOSITION 1 (Incomplete Ricardian Equivalence):

(i) If $\bar{d} \leq c_{2}^{*}$ then both candidates offer platforms with debt $\bar{d}$. Equilibrium consumption is $\left(c_{2}^{*}, c_{3}^{*}\right)$.

(ii) If $c_{2}^{*}<\bar{d}<c_{2}^{U}$ then both candidates offer platforms with debt $\bar{d}$. In equilibrium, second-period consumption is $c_{2}=\bar{d}$.

(iii) If $\bar{d} \geq c_{2}^{U}$ then any $d$ such that $c_{2}^{U} \leq d \leq k$ is part of an equilibrium. Equilibrium consumption is $\left(c_{2}^{U}, c_{3}^{U}\right)$.

\section{PROOF:}

(i) Assume by way of contradiction that equilibrium debt is $d^{*}<\bar{d}$. If this is the case, a voter can implement the commitment sequence of consumption $c_{2}^{*}, c_{3}^{*}$ by choosing $s_{12}=c_{2}^{*}-d^{*}$, and $s_{13}=c_{3}^{*}+d^{*}$. This is feasible since $d^{*}<\bar{d}<c_{2}^{*}$ and $c_{2}^{*}+c_{3}^{*}=k$. Hence, these are the optimal choices for the voter. But, by definition of $c_{2}^{*}, c_{3}^{*}, u^{\prime}\left(c_{2}^{*}\right)>\beta u^{\prime}\left(c_{3}^{*}\right)$, and therefore, in period 2 all voters would vote for a candidate who offered a slightly higher debt. Thus, the only debt that can be part of an equilibrium is $\bar{d}$. Given a debt of $\bar{d}$, in period 1 , each voter chooses $s_{12}=c_{2}^{*}-\bar{d}, s_{13}=c_{3}^{*}+\bar{d}$. Given these saving choices, none of the voters would vote for a candidate that offered a lower debt in the second period, proving that debt and this sequence of consumption constitute a unique equilibrium.

\footnotetext{
${ }^{19}$ In fact, the idea that the mere aggregation of different (standard) time preferences may generate a time inconsistent representative agent (or, consequently, a time inconsistent social planner) has been floating around since Marglin (1963) and Feldstein (1964). Sozou (1998) illustrated that hyperbolic discounting may emerge from exponentially distributed hazard rates; see Jackson and Yariv (forthcoming) for a generalization implying that non-dictatorial representative agents respecting Pareto efficiency are inherently time inconsistent.
} 
(ii) Assume by way of contradiction that, in equilibrium, a debt $d^{*}<\bar{d}$ is implemented. As in part (i), voters choose savings to restore commitment as much as possible. Assume that $c_{2}^{*}<d^{*}$ (otherwise, the proof of part (i) applies). Each agent maximizes

$$
\begin{aligned}
& \beta\left[u\left(c_{2}\right)+u\left(k-c_{2}\right)\right] \\
& \text { s.t. } c_{2} \geq d^{*} .
\end{aligned}
$$

The first order conditions yield

$$
\beta u^{\prime}\left(k-d^{*}\right)>u^{\prime}\left(c_{2}\right)=u^{\prime}\left(d^{*}\right)
$$

because $d^{*}>c_{2}^{*}\left(\right.$ recall that $\left.u^{\prime}\left(c_{2}^{*}\right)=u^{\prime}\left(c_{3}^{*}\right)\right)$. This means that the agent sets $s_{12}=0$ since second-period consumption is already higher than desired by the first-period self. However, since $d^{*}<c_{2}^{U}, u^{\prime}(d)>\beta u^{\prime}\left(c_{3}\right)$. Thus, in period 2 all voters would vote for higher debt contradicting the assumption that $d$ is an equilibrium debt level. Finally, to conclude that a debt of $\bar{d}$ is indeed part of an equilibrium, observe that, given $\bar{d}$, by similar reasoning, the optimal saving choices of all voters would lead to $u^{\prime}(\bar{d})>\beta u^{\prime}\left(c_{3}\right)$. Thus, no voter would vote for lower debt.

(iii) We first show that the claimed outcomes are part of an equilibrium. Given any candidate equilibrium debt $k>d^{*} \geq c_{2}^{U}$ that is expected by voters in period 1, an optimal policy of a voter in period 1 is a choice of $s_{12}=0$ and $s_{13}=k$. In addition, given $d^{*}$, in equilibrium, $s_{23}=d^{*}-c_{2}^{U}$ is to be saved in period 2 for period 3. Given this policy, by the definition of $c_{2}^{U}, c_{3}^{U}$, we have

$$
u^{\prime}\left(c_{2}^{U}\right)=\beta u^{\prime}\left(c_{3}^{U}\right)
$$

giving no incentive to any period-2 self to change her savings plan away from $s_{23}$.

Given these policies for the voters, consider a deviation to $d<d^{*}$ in period 2 . As long as the deviation is small $\left(d \geq c_{2}^{U}\right)$, all voters are indifferent (they can just make an offsetting reduction in $s_{23}$ to restore the desired consumption sequence). If the deviation is large $\left(d<c_{2}^{U}\right)$, then voters can no longer make such an offsetting reduction in $s_{23}$. All voters would therefore vote against a candidate offering such a deviation. A deviation to $d>d^{*}$ would leave all voters indifferent because they could make offsetting changes in $s_{23}$.

Consider now a candidate equilibrium debt $d^{*}<c_{2}^{U}$. Such an expected debt would constrain period-2 consumption for the voters, leading to victory in period 2 for a candidate offering $d>d^{*}$.

To gain intuition for this result, it is useful to first consider why zero debt is not an equilibrium. Suppose that individuals expect zero debt. Then, equilibrium outcomes would coincide with those in an economy with no government involvement, with agents committing to $\left(c_{2}^{*}, c_{3}^{*}\right)$. But then, in period 2, agents would find themselves 
constrained and would therefore vote for a candidate that offered positive debt. Next, consider increasing debt from step 1 (i.e., zero debt) and check if satisfying this initial demand for debt is sufficient to reach an equilibrium. Namely, let us set debt $d_{1}$ such that

$$
u^{\prime}\left(c_{2}^{*}+d_{1}\right)=\beta u^{\prime}\left(c_{3}^{*}-d_{1}\right) .
$$

This is the level of debt that is the equilibrium of the period-2 election given that savings are determined by individuals expecting zero debt and committing to their desired sequence of consumption. This clearly is not an equilibrium either: if agents expect debt $d_{1}$, they react by reducing $s_{12}\left(d_{1}\right)$ and increasing $s_{13}\left(d_{1}\right)$ to restore the commitment allocation. We can proceed to find the (higher) equilibrium secondperiod debt that will be demanded by voters given the lower savings for the second period. It is easy to see that this leads to $d_{2}=2 d_{1}$ (assuming that $2 d_{1}<\bar{d}$ and that $\left.c_{2}^{*}-d_{1} \geq 0\right)$.

When will this process stop? If the debt limit is binding, the process continues until debt hits the debt limit (parts (i) and (ii) of the proposition). If the debt limit is loose, the process continues until commitment is fully unraveled (case (iii)) because $s_{12}$ cannot go below zero.

In part (i) of this proposition, when the debt limit is low, voters can anticipate government debt and reduce savings intended for period 2 to restore the desired (commitment) sequence of consumption. The debt cap provides a form of commitment by the government not to succumb to individuals' revised preferences in later periods. ${ }^{20}$ Because of this saving behavior in period 1 , given any anticipated debt level in the feasible range, voters would like even higher debt in order to consume more in period 2 (they are endogenously liquidity constrained in period 2).

In contrast, in part (ii), equilibrium debt is sufficiently high that agents are no longer able to restore their desired commitment consumption sequence in period 1 . However, in period 2 voters are still constrained so they vote for candidates who offer maximal debt. Clearly, in the scenario depicted in Proposition 1, debt is no longer neutral.

In the case of part (iii), the debt cap $\bar{d}$ is large. In such cases, the government can no longer commit not to indulge agents' period 2 preferences and consumption is distorted relative to the optimal commitment levels. This result shows that, even when there are no distortions, if constraints on government action are loose, then government policy is distortionary because it interferes with individuals' ability to commit. Debt allows the government to undo the private commitments chosen by the voters in the prior period. Thus, the government acts as an enabler of the voters, substituting fiscal irresponsibility for private irresponsibility. Private commitments are not sufficient to induce consumption commitments: state commitment (such as tighter balanced budget constitutions) are essential. Agents' period 1 selves are made better off by tighter limits that lower $\bar{d}$ and restore their abilities to commit. ${ }^{21}$

\footnotetext{
${ }^{20}$ Note that the stark nature of this result relies on the fact that agents foresee perfectly their susceptibility to temptations. Commitments would only be partially restored if agents were not fully sophisticated.

${ }^{21}$ Notice that we implicitly assume that individuals cannot commit themselves into debt (they can assure a minimal wealth of zero in period 2). Were they able to commit themselves to a personal debt of up to $d_{P}$, the results of the proposition would carry through, with an appropriate shift of the debt limit by $d_{P}$.
} 
We now comment on Ricardian equivalence with time inconsistent agents. Clearly there is no general (global) Ricardian equivalence since, in different regions of the debt limit, consumption is different. However, there is a "local" version of Ricardian equivalence for sufficiently low debt limits. Furthermore, there is no "contemporaneous" Ricardian equivalence in cases (i) and (ii) of Proposition 1: if there is a surprise increase in the debt limit (and/or debt) in period 2, agents are unable to undo it by contemporaneous changes in their savings because they succumb to self-control problems. However, when debt limit is not too high (case (i)), voters can anticipate government debt and reduce savings intended for period 2 to restore the desired consumption sequence, which we view as a local Ricardian equivalence. In contrast, when the debt limit is loose there is a local Ricardian equivalence even with contemporaneous small debt changes: since agents are no longer able to commit for sufficiently loose debt limits, in equilibrium, second period consumption is optimal for second period selves and local changes in debt are fully undone by changes in second period savings.

The model is also useful for thinking about whether limits on gross debt have different effects than limits on net debt. In order to draw this distinction consider an extension of the model in which there are publicly owned assets of value $A$ that yield income in period 3 . For any given gross debt $D$ incurred in period 2 , net debt is by definition $D-A$. As long as $A$ is not too large $\left(A<c_{3}^{U}\right)$, and if there are no debt limits, then the equilibrium consumption sequence is independent of $A$, and gross debt is independent of $A$, but net debt decreases one for one with $A$. Thus, to be effective, debt limits must be set in terms of gross debt.

These results may seem closely related to the inefficiency of competitive credit markets when consumers are time inconsistent: even if consumers can buy illiquid assets to attempt to commit to a future consumption path, intermediaries such as credit card companies have the incentive to enter the market, leading to an undoing of commitment. ${ }^{22}$ However, the force underlying these results is quite different, and can lead to more dramatic inefficiencies. In order to see this we must move to a world with distortions. We discuss the comparison with private debt explicitly in Section IVA.

\section{B. Distortionary Debt}

In the environment considered up to now, debt was not directly distortionary: the distortions originated only from the effect of debt on individuals' private commitments.

We now consider the case in which government debt can be directly distortionary. There are a number of ways in which this can happen. For instance, debt could interfere with optimal smoothing of tax distortions, or because the small open economy assumption is violated, and debt has general equilibrium effects, or because the rate at which resources can be borrowed from abroad is high relative to citizens' discount rate.

In this initial analysis we assume a simple distortion: for every dollar taken in the form of debt in period 2, there is a tax $\eta$ that is paid in period 3 (and is therefore

\footnotetext{
${ }^{22}$ This point has been made by a number of authors. Gottlieb (2008) provides a detailed analysis of the effects of competition in markets with time inconsistent consumers.
} 
destroyed wealth). Thus, a per capita debt of $d$ taken in period 2 leads to $d(1+\eta)$ that needs to be repaid in period 3 . This is a reduced form way to capture distortions that could come from a variety of sources as mentioned above. ${ }^{23}$

Given savings from period 1 of $s_{12}$ and $s_{13}$, in period 2 a voter would choose debt to maximize $u\left(s_{12}+d\right)+\beta u\left(s_{13}-d(1+\eta)\right)$. The first order condition is $u^{\prime}\left(c_{2}\right)=\beta(1+\eta) u^{\prime}\left(c_{3}\right)$. In contrast, the analogous first order condition evaluated in period 1 is $u^{\prime}\left(s_{12}\right)=u^{\prime}\left(s_{13}\right)$. It follows that for any individual with preference parameter $\beta(1+\eta)<1$, period-2 self still wants to transfer resources from the third to the second period at the commitment solution.

The definition of optimal consumption levels now involves a subtlety that was absent in the case of no distortions: debt now destroys wealth so feasible consumption depends on debt. Let $c_{2}^{*}(d)$ and $c_{3}^{*}(d)$ be the commitment sequence of consumption given debt $d$, namely, the solution to the following problem:

$$
\begin{aligned}
& \max \beta\left[u\left(c_{2}\right)+u\left(c_{3}\right)\right] \\
& \text { s.t. } c_{2}+c_{3} \leq k-\eta d .
\end{aligned}
$$

Analogously, let $c_{2}^{U}(d)$ and $c_{3}^{U}(d)$ be the corresponding quantities without commitment.

Notice that the Theorem of the Maximum guarantees that both the commitment and the no-commitment consumption sequences are continuous in $d$. They are also all decreasing functions of $d$.

As in the case of no distortions, the behavior of equilibrium debt and consumption is divided into three regions depending on the debt limit. In order to determine the limits of these regions we need to define two values of debt that we call $d^{*}$ and $d^{* *}$.

Define $d^{*}$ as the solution of $c_{2}^{*}\left(d^{*}\right)=d^{*} .24$

We now introduce an artificial constrained-maximization problem for a voter of preference parameter $\beta(1+\eta)<1$ :

$$
\begin{aligned}
& \max \beta\left[u\left(c_{2}\right)+u\left(c_{3}\right)\right] \\
& \text { s.t. } u^{\prime}\left(c_{2}\right)=\beta(1+\eta) u^{\prime}\left(c_{3}\right), \\
& c_{2}+c_{3} \leq k-d \eta .
\end{aligned}
$$

The first constraint is a "relaxed" commitment constraint, where resources transferred between periods 3 and 2 are costly. This will be the relevant constraint in determining debt in the second period. The smaller the distortion $\eta$, the tighter this constraint. The second constraint reflects the loss of resources due to the distortion. Denote by $\left(c_{2}^{\eta}(d), c_{3}^{\eta}(d)\right)$ the consumption sequence that solves the problem.

\footnotetext{
${ }^{23}$ Of course, there is no particular reason to expect these distortions to be proportional. This is assumed mainly for convenience. The qualitative analysis of this section does not depend on this assumption. We consider convex distortions in online Appendix, Section B, and show that some of the main features remain unchanged.

${ }^{24}$ Notice that $c_{2}^{*}(0) \geq 0$, while $c_{2}^{*}(k / \eta)=0<k / \eta$, and so the Intermediate Value Theorem guarantees the existence of such a $d^{*}$.
} 
Note that, in equilibrium, the wealth constraint is binding. Therefore, the solution is entirely determined by the two constraints. We now define $d^{* *}$ to be the solution of $d^{* *}=c_{2}^{\eta}\left(d^{* *}\right) \cdot{ }^{25}$ It is easy to show that $d^{*}<d^{* *}$.

PROPOSITION 2 (Distortionary Equilibrium Debt):

(i) If $\beta(1+\eta)>1$ then in equilibrium there is no debt and consumption is given by $\left(c_{2}^{*}, c_{3}^{*}\right)$.

(ii) Assume that $\beta(1+\eta)<1$. If $\bar{d} \leq d^{*}$, then equilibrium debt is given by $\bar{d}$ and consumption is given by $\left(c_{2}^{*}(\bar{d}), c_{3}^{*}(\bar{d})\right)$. If $d^{*}<\bar{d} \leq d^{* *}$, then equilibrium debt is given by $\bar{d}$ and period 2 consumption is given by $c_{2}=\bar{d}$. If $\bar{d}>d^{* *}$, then debt is given by $d^{* *}$ and period 2 consumption is given by $c_{2}=d^{* *}$.

\section{PROOF:}

(i) We first show that there is an equilibrium with zero debt. Given an expected second-period debt of zero, in period 1 voters choose the mix of liquid and illiquid assets $s_{12}=c_{2}^{*}$ and $s_{13}=c_{3}^{*}$ that implements the commitment consumption sequence $\left(c_{2}^{*}, c_{3}^{*}\right)$. Given this mix of savings, $u^{\prime}\left(c_{2}^{*}\right)=u^{\prime}\left(c_{3}^{*}\right)$. Thus, if $\beta(1+\eta)>1, u^{\prime}\left(c_{2}^{*}\right)<\beta(1+\eta) u^{\prime}\left(c_{3}^{*}\right)$ and voters have no incentive to vote for positive debt. Consider now any level of expected debt $d$. The mix of savings has to be such that $u^{\prime}\left(s_{12}+d\right) \leq u^{\prime}\left(s_{13}+s_{23}-d\right)$. But then $u^{\prime}\left(s_{12}+d\right)<$ $\beta(1+\eta) u^{\prime}\left(s_{13}+s_{23}-d\right)$, inducing voters to vote to reduce debt.

(ii) Consider now the case in which $\beta(1+\eta)<1$. Given any $\bar{d}<d^{*}$ and any expected debt $d \leq \bar{d}$, optimal savings in period 2 are given by $s_{23}=0$ and $s_{12}, s_{13}$ are such that $u^{\prime}\left(s_{12}+d\right)=u^{\prime}\left(s_{13}-d\right)$. Thus, $u^{\prime}\left(s_{12}+d\right)>$ $\beta(1+\eta) u^{\prime}\left(s_{13}-d\right)$ and voters would vote to increase debt. Thus, in this scenario equilibrium debt must be $\bar{d}$ and consumption must be given by $\left(c_{2}^{*}(\bar{d}), c_{3}^{*}(\bar{d})\right)$. If $d^{*}<\bar{d} \leq d^{* *}$, then, by the same reasoning, equilibrium debt must be at least $d^{*}$. But then, by the definition of $d^{*}$, debt is higher than second-period commitment consumption, and optimal savings are at a corner: $s_{12}=s_{23}=0$, implying that $c_{2}=d$. Because $d<d^{* *}$, we then have that $\beta(1+\eta) u^{\prime}\left(c_{3}\right)<u^{\prime}\left(c_{2}\right)<u^{\prime}\left(c_{3}\right)$. This implies that voters vote for higher debt unless $d=\bar{d}$. Finally, If $\bar{d} \geq d>d^{* *}$, then by the definition of $d^{* *}, u^{\prime}(d)<\beta(1+\eta) u^{\prime}\left(c_{3}\right)$, so voters would vote to reduce debt. This proves that for any $\bar{d} \geq d^{* *}$ equilibrium debt is given by $d^{* *}$.

This result says that debt accumulation can result in very large distortions when voters suffer from self control problems. The intuition is fairly similar to the one that we described for the case of no distortions, and a similar iteration of steps can be illustrated for this case. Because debt is determined by voters' collective choices,

${ }^{25}$ Again, the Intermediate Value Theorem assures that such $d^{* *}$ always exists since $c_{2}^{\eta}(0)=c_{2}^{U}(0) \geq 0$, and $c_{2}^{\eta}(k / \eta)=0<k / \eta$, and the Theorem of the Maximum implies that $c_{2}^{\eta}(d)$ is continuous. 
individual saving decisions in prior periods have no impact on debt: voters have an incentive to try to undo expected second-period debt by optimizing their mix of liquid-illiquid assets by saving less for period 2 and more for period 3. But, when the debt ceiling is not too low, this individual optimization will, in the aggregate, generate demand for transfers in the second period, leading to voting for a positive debt. Thus, savings decisions in period 1 generate their own demand for debt in the second period, even when debt is distortionary.

\section{Institutions, Welfare, and Policy}

We now evaluate how welfare in the equilibrium allocation presented in Proposition 2 compares with several alternative benchmarks/policies. We consider: (i) private debt incurred via market intermediaries; (ii) a social planner without commitment; (iii) banning of illiquid assets, thereby eliminating commitment possibilities; and (iv) tighter debt limits.

In order to evaluate these scenarios, it is useful to understand the welfare consequences of distortions. The following result provides a comparison of equilibrium welfare with and without distortions, as well as the effects of changes in the level of distortions.

PROPOSITION 3.1 (Welfare Effects of Distortions):

(i) Suppose $\beta(1+\eta)>1$. Then welfare for the period one self is higher than for any $\eta$ such that $\beta(1+\eta)<1$.

(ii) Suppose $\beta(1+\eta)<1$. If $\bar{d} \geq d^{* *}$, and if the coefficient of relative risk aversion is greater than 1 (i.e., $\left.-c \frac{u^{\prime \prime}(c)}{u^{\prime}(c)}>1\right)$, then consumption is decreasing in $\eta$ in both periods and welfare is decreasing in $\eta$ for all three selves.

The proof of this proposition is in the Appendix. As mentioned above, there are two contrasting effects of positive distortions. On the positive side, distortions relax the commitment constraint in the artificial maximization that determines equilibrium debt. In fact, when $\eta$ is very high (i.e., $\beta(1+\eta)>1$ ), distortions serve as a full commitment device since, in equilibrium, voters do not vote for positive debt in the second period. In that case, first period welfare is maximal. On the negative side, given that there is debt in equilibrium, the presence of distortions causes wealth destruction. In fact, for the range of parameters such that the debt limit is binding, debt does not depend on $\eta$ and there is no commitment value of increasing $\eta$. When the debt limit is not binding the two effects play against each other. Nonetheless, as the proposition illustrates, for a large class of utilities, the impact of distortions on wealth overwhelms their commitment benefits and, when $\beta(1+\eta)<1$, welfare can be decreasing for all period selves in the level of distortions $\eta$. We stress that the proof illustrates that whenever $\beta(1+\eta)<1$, second-period consumption is always decreasing in $\eta$ regardless of the coefficient of risk aversion. The restriction on relative risk aversion guarantees that $c_{3}$ is decreasing in $\eta$ as well, implying that welfare in all periods is decreasing in $\eta$. In general, this restriction is sufficient, but 
not necessary. With CRRA utility, period 1 welfare increases in $\eta$ only if the coefficient of relative risk aversion is very close to zero and $\beta(1+\eta)$ is very close to one. Nonetheless, with CRRA utility, period 3 welfare, or $c_{3}$, is decreasing in $\eta$ if and only if the coefficient of relative risk aversion is greater than 1 , coinciding with the restriction in the proposition.

The proposition focuses on high debt limits. When the debt limit is very low, there is a different channel by which distortions affect welfare negatively. Namely, for a sufficiently low debt limit, the debt limit is binding regardless of the levels of distortions (as long as $\beta(1+\eta)<1$ ). In that case, since second-period consumption is decreasing in distortions (from the proof of Proposition 1), welfare is decreasing in the level of distortions for all selves. That is, we have the following:

PROPOSITION 3.2 (Welfare Effects of Distortions for Low Debt Limits): There exists $\hat{d}<d^{* *}$ such that, if $\bar{d} \leq \hat{d}$, consumption is decreasing in $\eta$ in both periods and welfare is decreasing in $\eta$ for all three selves.

We include the formal proof of Proposition 2 in the Appendix. We stress that the corollary does not describe a knife-edge case, $\hat{d}$ is a function of $\beta$, which is strictly positive for all $\beta \in(0,1)$.

As a last note, if we allowed agents to consume in period 1, then these results would take a different form but the main idea would be fairly similar (see online Appendix, Section D, for details).

\section{A. Private Debt versus Public Debt}

Consider now an environment in which there is no government but individuals can borrow on the private market from intermediaries such as credit card companies. The model is otherwise the same as in Section III. For the purposes of comparison with our analysis of government debt, assume that credit card companies charge a proportional fee $\hat{\eta}$ for every dollar borrowed in the second period. This could be due to markups in an imperfectly competitive credit market or to costs born by credit card companies. We do not claim that this is a rich and realistic model of credit card debt with self control. The point of this stark model is to draw an important contrast between private and public debt. The contrast is particularly pronounced when there is no debt limit.

Given $s_{12}, s_{13}=k-s_{12}$, in the second period the agent chooses $d$ to maximize $u\left(s_{12}+d\right)+\beta u\left(s_{13}-d(1+\eta)\right)$ subject to the budget constraint and non negativity constraints for savings $s_{12} \geq 0, s_{13} \geq 0$. Let $d\left(s_{12}, s_{13}\right)$ denote the solution to this problem.

In the first period, the agent solves the following problem:

$$
\begin{gathered}
\max _{s_{12}, s_{13}} \beta\left[u\left(s_{12}+d\left(s_{12}, s_{13}\right)\right)+u\left(s_{13}-d\left(s_{12}, s_{13}\right)(1+\eta)\right)\right] \\
\text { s.t. } s_{12}+s_{13} \leq k-d\left(s_{12}, s_{13}\right) \eta, \ldots s_{12} \geq 0, s_{13} \geq 0 .
\end{gathered}
$$


PROPOSITION 4 (Equilibrium with Credit Cards):

(i) If $\beta(1+\eta)>1$ then in equilibrium there is no debt and consumption is given by $\left(c_{2}^{*}, c_{3}^{*}\right)$.

(ii) Assume that $\beta(1+\eta)<1$ and that there is no debt limit. Agents make portfolio decisions in period 1 that ensure no debt in the second period: equilibrium debt is zero, equilibrium consumption is given by $\left(c_{2}^{\eta}(0), c_{3}^{\eta}(0)\right)$, and first-period welfare is increasing in $\eta$.

\section{PROOF:}

If $\beta(1+\eta)>1$, then at $\left(c_{2}^{*}, c_{3}^{*}\right)$ the agent does not wish to borrow in the second period. Thus, in the first period the agent chooses savings $\left(c_{2}^{*}, c_{3}^{*}\right)$.

Assume now that $\beta(1+\eta)<1$. Suppose $\hat{s}_{12}, \hat{s}_{13}$, and $d\left(\hat{s}_{12}, \hat{s}_{13}\right)>0$ constitute part of an equilibrium. Since there is no debt limit, the second period first-order condition of the agent must hold, and therefore we must have:

$$
u^{\prime}\left(\hat{s}_{12}+d\left(\hat{s}_{12}, \hat{s}_{13}\right)\right)=\beta(1+\eta) u^{\prime}\left(\hat{s}_{13}-d\left(\hat{s}_{12}, \hat{s}_{13}\right)(1+\eta)\right) .
$$

The following savings plan constitutes an improvement plan in period 1: $s_{12}=\hat{s}_{12}+$ $d\left(\hat{s}_{12}, \hat{s}_{13}\right), s_{13}=\hat{s}_{13}-d\left(\hat{s}_{12}, \hat{s}_{13}\right)(1+\eta)$. Given this savings plan, the second period's first-order conditions are satisfied with $d\left(s_{12}, s_{13}\right)=0$ and consumption at $t=2$ and $t=3$ is unchanged. However, this saving plan increases the resources available to the consumer in period 1 by $\eta d\left(\hat{s}_{12}, \hat{s}_{13}\right)$. These can be distributed between periods 2 and 3, while still satisfying the first order condition. In particular, $\left(c_{2}^{\eta}(0), c_{3}^{\eta}(0)\right)$ is the resulting consumption sequence that clearly satisfies the second period's first-order condition.

The logic of this result is the following. The availability of credit in the second period limits the commitment possibilities for time-inconsistent agents. However, sophisticated agents anticipate this issue and take appropriate steps to counteract this temptation. Every consumption profile that is attainable via positive debt with credit cards is also attainable with an appropriate mix of liquid-illiquid assets. Thus, with positive distortions and loose debt limits it cannot be optimal to ever end up with positive credit card debt. Agents internalize the commitment constraint in period 2 and "give up on commitment" just enough so that they do not waste resources by dealing with credit card companies. Clearly, first period welfare is increasing in $\eta$ because higher $\eta$ relaxes the commitment constraint.

With a debt limit, the consumer may, in equilibrium, accumulate debt because the debt limit allows him to retain some commitment ability: if the debt limit is particularly tight, then the consumer is willing to give up some resources in order to achieve commitment. However, when the debt limit is loose the cost is too large and therefore the consumer gives up trying to commit. This case is discussed in detail in the online Appendix.

Agents' sophistication is important for this characterization to hold. Indeed, were agents naïve, believing their future selves will face no self-control problems, Heidhues and Köszegi (2010) illustrate a reverse pattern of welfare with respect to 
repayment penalties. In their setting, naïve agents do not foresee taking any future debt and so the higher the repayment penalties, the greater the actual future cost agents end up paying. The commitment benefits of high distortions (high $\eta$ ) in our model are completely lost on naïve agents. However, there is an important difference in terms of the contract space between our setting and that studied in Heidhues and Kőszegi (2010). In their environment, contracts are exclusive, allowing sophisticates to implement the efficient outcome, whereas in our model, agents can buy any asset amount at a fixed unit price and agents' ability to borrow at a positive markup breaks down their commitment power.

Part (ii) of this result contrasts Proposition 1. The key difference is that public debt is a result of collective action, so individuals have a private incentive to undo public debt.

We have discussed private debt and public debt separately, assuming that debt is either public or private but not both. One can easily examine a model with coexistence of private and public debt. In our model with linear distortions, the coexistence yields uninteresting results. Let $\eta_{G}$ be the distortion associated with public debt and $\eta_{P}$ the distortion (markup) associated with private debt. Then, if $\eta_{G}<\eta_{P}$, it is possible to show that only public debt matters. If $\eta_{G}>\eta_{P}$, then only private debt matters. It is not clear what assumption is more reasonable (e.g., interest rates on credit card debt often exceed 20 percent). ${ }^{26}$ This result hinges on the linearity of the distortions. It can in fact be shown that if distortions are convex, then private debt and public debt coexist. However, the model is much more complicated in this case. ${ }^{27}$

\section{B. Social Planner without Commitment}

In the environment we study, voters are time inconsistent while politicians simply pursue office in each period. As an alternative, consider a situation in which a time-inconsistent social planner, sharing the population preference parameter $\beta$, fully determines consumption allocations. Notice that this would correspond to the decision process emerging in a citizen-candidate version of our model. As for the case of private debt, it is easy to see that the allocation determined by such a social planner, at least for sufficiently high debt limits, is given by $\left(c_{2}^{\eta}(0), c_{3}^{\eta}(0)\right)$, namely by the solution of the maximization problem given in (2). Therefore, first-period welfare is increasing in $\eta$ since higher distortions lessen the commitment constraint. ${ }^{28}$ This is clearly in stark contrast with the result in Proposition 1. As we pointed out before, however, a social planner who only controls aggregate intertemporal transfers and cannot control individual portfolio allocations would behave exactly as our politicians, leading to the same equilibrium as the political

\footnotetext{
${ }^{26}$ Notice that when private and public debt are both available, there can be a multiplicity of equilibria. Indeed, if no one takes on private debt at the outset, there is no demand for public debt later on (and any agent putting themselves into private debt at the beginning will not be able to repay). If everyone takes on private debt, there is a collective demand for public debt later on, which sustains the initial individual private demands for debt.

${ }^{27}$ See Angeletos et al. (2001) for a model with coexistence of credit card debt and investment in illiquid assets.

${ }^{28}$ Krusell et al. (2002) show that in an economy with capital accumulation there is an additional issue in contrasting a decentralized economy and a social planner without commitment. Specifically, while individuals take the returns to savings as given, the social planner takes into account the fact that, with decreasing returns, increased aggregate savings reduce returns to capital accumulation. This leads to even worse undersaving when a social planner is present.
} 
economy one. Thus, in our setting, there is an interesting non-monotonicity in the effect of government intervention: moderate government intervention in the form of debt-financed transfers leads to worse outcomes than either decentralized allocations or fully centralized allocations.

\section{Period 1 Financial Structure}

We now consider the socially optimal mix of liquid and illiquid assets when government may act in a fiscally irresponsible manner. A common argument in the behavioral literature is that in environments with time-inconsistent agents, an efficiency enhancing paternalistic policy is to subsidize or otherwise promote the existence of illiquid commitment assets.

Our results suggest that, in evaluating such policies, it is important to consider how this affects the political economy of debt.

When agents have no access to illiquid assets they have no commitment power. This can arise whenever, say, agents have access to personal credit cards (with a rate of return of 1) that allow them to undo any commitment plan they entered in earlier periods. Alternatively, whenever agents have access to illiquid assets and debt is non-distortionary and has no limit, agents are effectively tied to uncommitted consumption paths. The comparison with such environments is less straightforward since it presents a trade-off. On the one hand, debt allows for some level of commitment when illiquid assets are available. On the other hand, it entails a wealth loss. Specifically, in our model, an implication of Proposition 1 is that welfare is higher for all selves when illiquid assets are banned or taxed, rather than subsidized.

PROPOSITION 5 (Banning Illiquid Assets): Suppose $\bar{d}>d^{* *}$ and assume $\beta(1+\eta)<1$. Whenever the coefficient of relative risk aversion is greater than 1 , the welfare corresponding to all selves is higher if illiquid assets are banned.

Of course, this result should be evaluated with caution since there may be many reasons why the personal benefits of commitment are not offset by subsequent increases of government debt. However, it provides a useful additional effect to be aware of when evaluating the appropriate asset mix. The result easily extends to allow for some heterogeneity in $\beta$. As long as the heterogeneity is not too large, all selves of all agents are made better off by eliminating illiquid assets. We discuss the effects of heterogeneity in the online Appendix. We analyze a more general financial structure in more detail below.

In our previous analysis we have assumed that liquid and illiquid assets have constant returns and that these returns are equal. We have also assumed that illiquidity is absolute. We now discuss how the analysis generalizes.

First, note that it is straightforward to allow for special cases of partial liquidity. For instance, assume that there is a linear cost of liquidating assets in period 2, and let $\lambda$ be the marginal cost of liquidation. If $\eta<\lambda$, it is easy to see that the equilibrium is the same as the one characterized in Proposition 2 where we assume $\lambda=\infty$. The reason is that at the equilibrium characterized in Proposition 2 agents do not wish to transfer resources from period 3 to period 2 taking into account the fact that transferring resources through government debt destroys $\eta$ at the margin. 
This implies that they also do not wish to transfer such resources by liquidating their illiquid assets at an even higher cost of $\lambda$. If, on the other hand, $\eta>\lambda$, then in equilibrium there would be no government debt. These results hinge on the linearity of the distortions. It can in fact be shown that if both distortions are convex (and the marginal distortions are zero at zero), then there would be both public debt and some costly liquidation, just as we discussed for the case of coexistence of private and public debt. However, the model is much more complicated in this case.

Our analysis can also readily be extended to allow for a more general structure of returns. First of all, it can easily be seen that assuming that the returns are lower for the illiquid assets is equivalent to assuming a larger debt distortion $\eta$.

Second, we consider the case of decreasing returns in investment. Let $R_{L}(s)$ and $R_{I}(s)$ denote the returns on liquid and illiquid assets, respectively, as a function of the investment $s$. We assume that $R_{L}(0) \geq 1, R_{I}(0) \geq 1, R_{L}(k)<\beta$, and $R_{I}(k)<\beta$. Suppose that $R_{L}^{\prime}(s)$ and $R_{I}^{\prime}(s)$ are both negative. We also assume that there is no debt distortion, to focus on the novel distortion introduced by decreasing returns.

Given debt $d$, an individual chooses $s_{12}$ and $s_{13}$ to maximize

$$
\begin{aligned}
& \beta\left[u\left(R_{L}\left(s_{12}\right) s_{12}+d\right)+u\left(R_{I}\left(s_{13}\right) s_{13}-d\right)\right] \\
& \text { s.t. } s_{12}+s_{13} \leq k .
\end{aligned}
$$

Furthermore, electoral competition requires that, if there are no debt limits, debt $d$ in the second period is chosen to satisfy the first order condition of the political economy problem,

$$
u^{\prime}\left(R_{L}\left(s_{12}\right) s_{12}+d\right)=\beta u^{\prime}\left(R_{I}\left(s_{13}\right) s_{13}-d\right), \quad s_{13}=k-s_{12} .
$$

There are two possibilities for the characterization of the equilibrium. We can have a corner solution where $s_{12}=0$. This happens if decreasing returns are not very severe. If instead decreasing returns are sufficiently pronounced, then equilibrium is pinned down by the first period condition of problem (3). Let $\gamma_{L}(s)$ and $\gamma_{I}(s)$ denote the marginal returns on liquid and illiquid assets, respectively,

$$
\gamma_{L}(s) \equiv R_{L}(s)+R_{L}^{\prime}(s) s, \gamma_{I}(s) \equiv R_{I}(s)+R_{I}^{\prime}(s) s
$$

The first order conditions corresponding to (3) are

$$
\gamma_{L}\left(s_{12}\right) u^{\prime}\left(R_{L}\left(s_{12}\right) s_{12}+d\right)=\gamma_{I}\left(s_{13}\right) u^{\prime}\left(R_{I}\left(s_{13}\right) s_{13}-d\right)
$$

From (4) we obtain that, at an equilibrium level of debt, we must have

$$
\frac{\gamma_{I}\left(s_{13}\right)}{\gamma_{L}\left(s_{12}\right)}=\beta, \quad s_{13}=k-s_{12} .
$$

It is useful to consider the special case in which the returns to both assets are identical: $R_{L}=R_{I}=R$ and $\gamma_{I}=\gamma_{L}=\gamma$. 
In the case in which there is no government intervention this simplifies the solution because the first order conditions of the individual agent's problem with commitment must be solved by $s_{12}=s_{13}$ and hence,

$$
\frac{\gamma\left(s_{13}\right)}{\gamma\left(s_{12}\right)}=1, \quad s_{13}=k-s_{12} .
$$

Equation (5) then implies that in the political economic equilibrium individuals face a lower return at the margin as a consequence of investing too much in the illiquid asset. Therefore, there is a waste of resources.

We now consider the effects of taxing the returns on illiquid assets. Let $\phi$ be the unit tax. Then, for given $s_{12}, s_{13}$, the political economy equilibrium gives the first order conditions

$$
u^{\prime}\left(R\left(s_{12}\right) s_{12}+d+\frac{\Phi}{2}\right)=\beta u^{\prime}\left(\left(R\left(s_{13}\right)-\phi\right) s_{13}-d+\frac{\Phi}{2}\right),
$$

where $\Phi$ is the total revenues from taxes, which we assume is reimbursed lumpsum and equally across the two periods. Given $d$, each agent chooses $s_{12}$ and $s_{13}$ to maximize

$$
\begin{aligned}
& \beta\left[u\left(R\left(s_{12}\right) s_{12}+d+\frac{\Phi}{2}\right)+u\left(\left(R\left(s_{13}\right)-\phi\right) s_{13}-d+\frac{\Phi}{2}\right)\right] \\
& \text { s.t. } s_{12}+s_{13} \leq k .
\end{aligned}
$$

This leads to the following first order condition:

$$
\gamma\left(s_{12}\right) u^{\prime}\left(R\left(s_{12}\right) s_{12}+d+\frac{\Phi}{2}\right)=\left(\gamma\left(s_{13}\right)-\phi\right) u^{\prime}\left(\left(R\left(s_{13}\right)-\phi\right) s_{13}-d+\frac{\Phi}{2}\right)
$$

with $s_{12}+s_{13}=k$. Substituting from the condition for the political equilibrium, we obtain

$$
\frac{\gamma\left(s_{13}\right)-\phi}{\gamma\left(s_{12}\right)}=\beta, \quad s_{13}=k-s_{12}
$$

These taxes lead to lower investment distortions by reducing investment in illiquid assets, which in turn leads to a reduction of the debt in the second period. Thus, in this equilibrium, when we introduce taxes on illiquid assets we still have $u^{\prime}\left(c_{2}\right)=\beta u^{\prime}\left(c_{3}\right)$ so the self-control problem is unavoidable. However, when $\phi$ is high, this intertemporal condition is satisfied by lower levels of $s_{13}$ and lower levels 
of debt. Thus, there are values of $\phi$ that lead to greater efficiency by reducing excessive investment in illiquid assets (and reducing debt).

An alternative interpretation of $\phi$ is as a friction (or a subsidy) in the market for illiquid assets such as housing. This interpretation provides an interesting empirical implication of the model: the higher these frictions, the lower the investment in illiquid assets and the lower the level of government debt. Thus, the model generates a relation between agents ease of investment in illiquid assets, the level of such investments (e.g., housing) and the amount of government debt. Conversely, higher subsidies to illiquid investments lead, in the equilibrium of our model, to higher government debt.

\section{Concluding Remarks}

We introduced a political process determining fiscal policy when voters are time inconsistent. Several messages arise from our analysis. First, absent distortions, as long as debt limits are low enough, the availability of illiquid assets makes debt irrelevant for ultimate consumption levels since agents can adjust foreseen debt income by an appropriate ex ante allocation of liquid and illiquid assets. In particular, there is a Ricardian equivalence of sort. When debt limits are high, agents' ability to commit is impaired. That is, electorally accountable politicians ultimately choose policies that interfere with individuals' ex ante desire to commit. When debt is distortionary some of these effects are accentuated since debt entails an effective loss of wealth. In fact, we show that there can be a substantial loss in welfare relative to the case of a world without any ability to commit and without debt. The paper highlights the importance of analyzing the political process when contemplating enlarging the menus of policies directed at enhancing the welfare of "behavioral" electorates.

We have focused on a three period model to highlight the key forces driving the results. In online Appendix, Section B, we discuss the case in which we allow for an arbitrary (finite) number of periods as well as for convex distortions from taxation. Convex distortions induce debt repayments to be smoothed over time: we show that the equilibrium features a debt accumulation phase, where individuals consume exclusively out of government transfers, and a repayment phase where there are no additional transfers. We then show that when the number of periods approaches infinity, even when endowment per period remains fixed, the size of the debt becomes arbitrarily large. This is the case, of course, unless debt limits are imposed. In other words, debt limits are necessary to limit the inefficient distortions which the economy must incur to repay large accumulated debts at equilibrium.

\section{APPENDIX}

\section{PROOF OF PROPOSITION 3.1:}

If $\beta(1+\eta)>1$, then by Proposition 2, there is no debt and the consumption sequence is the one under full commitment. Thus, the period 1 self's welfare is maximized: welfare under any other $\eta$ must be lower. 
Suppose $\beta(1+\eta)<1$ and that $\bar{d}>d^{* *}$. It follows from the characterization of equilibrium in Proposition 2, that at equilibrium with no debt limits $c_{2}=d^{* *}$; that is, $s_{12}=0$. As a consequence, equilibrium consumption reduces to the solution of the following maximization problem:

$$
\begin{gathered}
\max _{c_{2}, c_{3}} \beta\left[u\left(c_{2}\right)+u\left(c_{3}\right)\right] \\
\text { s.t. } u^{\prime}\left(c_{2}\right)=\beta(1+\eta) u^{\prime}\left(c_{3}\right) \\
c_{2}+c_{3} \leq k-\eta c_{2} .
\end{gathered}
$$

Note that at the solution of problem (6), the budget constraint will hold with equality. The solution, therefore, is determined uniquely by the constraints and will satisfy

$$
u^{\prime}\left(c_{2}\right)=\beta(1+\eta) u^{\prime}\left(k-(1+\eta) c_{2}\right)
$$

From the Implicit Function Theorem and since $u^{\prime}(c)>0, u^{\prime \prime}(c)<0$ for all $c$,

$$
\frac{d c_{2}}{d \eta}=-\frac{-\beta u^{\prime}\left(k-(1+\eta) c_{2}\right)+\beta(1+\eta) c_{2} u^{\prime \prime}\left(k-(1+\eta) c_{2}\right)}{u^{\prime \prime}\left(c_{2}\right)+\beta(1+\eta)^{2} u^{\prime \prime}\left(k-(1+\eta) c_{2}\right)}<0
$$

Similarly, we can write the constraints in terms of $c_{3}$ :

$$
u^{\prime}\left(\frac{k-c_{3}}{1+\eta}\right)=\beta(1+\eta) u^{\prime}\left(c_{3}\right)
$$

and using the Implicit Function Theorem again,

$$
\begin{aligned}
\frac{d c_{3}}{d \eta}= & \\
& -\left(-\frac{k-c_{3}}{(1+\eta)^{2}} u^{\prime \prime}\left(\frac{k-c_{3}}{1+\eta}\right)-\beta u^{\prime}\left(c_{3}\right)\right) /\left(-\frac{1}{1+\eta} u^{\prime \prime}\left(\frac{k-c_{3}}{1+\eta}\right)-\beta(1+\eta) u^{\prime \prime}\left(c_{3}\right)\right) .
\end{aligned}
$$

Since $u^{\prime \prime}<0$, the sign of $\frac{d c_{3}}{d \eta}$ coincides with the sign of

$$
\frac{k-c_{3}}{(1+\eta)^{2}} u^{\prime \prime}\left(\frac{k-c_{3}}{1+\eta}\right)+\beta u^{\prime}\left(c_{3}\right)
$$

which, by multiplying by $1+\eta$, has the same sign as

$$
c_{2} u^{\prime \prime}\left(c_{2}\right)+\beta(1+\eta) u^{\prime}\left(c_{3}\right)
$$

Since $\beta(1+\eta)<1$ and $u^{\prime}\left(c_{3}\right)>0$,

$$
c_{2} \frac{u^{\prime \prime}\left(c_{2}\right)}{u^{\prime}\left(c_{3}\right)}+\beta(1+\eta)<c_{2} \frac{u^{\prime \prime}\left(c_{2}\right)}{u^{\prime}\left(c_{3}\right)}+1
$$


Notice that the second period constraint implies that $c_{2}>c_{3}$, and therefore $u^{\prime}\left(c_{3}\right)>u^{\prime}\left(c_{2}\right)$. Therefore,

$$
c_{2} \frac{u^{\prime \prime}\left(c_{2}\right)}{u^{\prime}\left(c_{3}\right)}<c_{2} \frac{u^{\prime \prime}\left(c_{2}\right)}{u^{\prime}\left(c_{2}\right)}
$$

The restriction that the coefficient of relative risk aversion is greater than 1 therefore assures that $\frac{d c_{3}}{d \eta}<0$. Since $\frac{d c_{2}}{d \eta}<0$, it follows that welfare of all selves decreases with the distortion level $\eta$.

\section{PROOF OF PROPOSITION 3.2:}

Since the proposition illustrates that whenever $\beta(1+\eta)<1$, second-period consumption is decreasing in $\eta$, we can also deduce the impacts of distortions on welfare for low debt limits. Indeed, by Proposition 2 , if $\bar{d} \leq d^{* *}$, equilibrium debt is equal to $\bar{d}$. Furthermore, for $d^{*} \leq \bar{d} \leq d^{* *}, c_{2}=\bar{d}$. Since $c_{2}$ is decreasing in $\eta$ when $\beta(1+\eta)<1$, the lowest possible level of consumption in period 2 is attained in the limit as $\eta \rightarrow \frac{1-\beta}{\beta}$. Define $\hat{d}$ to be equal to this level of $c_{2}$. For values of $\bar{d}<\hat{d}$, the debt limit is binding regardless of the value of $\eta$. Thus, the equilibrium level of debt is given by the debt limit for all values of $\eta$. In this region, therefore, increasing the value of $\eta$ reduces the value of both $c_{2}$ and $c_{3}$. The statement of the proposition then follows.

\section{REFERENCES}

Alesina, Alberto, and Guido Tabellini. 1990. "Voting on the Budget Deficit." American Economic Review 80 (1): 37-49.

-Amador, Manuel, Ivan Werning, and George-Marios Angeletos. 2006. "Commitment vs. Flexibility." Econometrica 74 (2): 365-96.

-Angeletos, George-Marios, David Laibson, Andrea Repetto, Jeremy Tobacman, and Steven Weinberg. 2001. "The Hyperbolic Consumption Model: Calibration, Simulation, and Empirical Evaluation." Journal of Economic Perspectives 15 (3): 47-68.

Augenblick, Ned, Muriel Niederle, and Charles Sprenger. 2013. "Working Over Time: Dynamic Inconsistency in Real Effort Tasks." Unpublished.

Battaglini, Marco, and Steven Coate. 2008. "A Dynamic Theory of Public Spending, Taxation, and Debt." American Economic Review 98 (1): 201-36.

-Bénabou, Roland, and Jean Tirole. 2006. "Belief in a Just World and Redistributive Politics." Quarterly Journal of Economics 121 (2): 699-746.

Bendor, Jonathan, Daniel Diermeier, David A. Siegel, and Michael M. Ting. 2011. A Behavioral Theory of Elections. Princeton, NJ: Princeton University Press.

Benjamin, Daniel J., and David I. Laibson. 2003. "Good Policies For Bad Governments: Behavioral Political Economy." Unpublished.

Bleichrodt, Han, and Magnus Johannesson. 2001. "Time Preference for Health: A Test of Stationarity versus Decreasing Timing Aversion.” Journal of Mathematical Psychology 45 (2): 265-82.

Cairns, John A., and Marjon van der Pol. 1997. "Saving Future Lives. A Comparison of Three Discounting Models." Health Economics 6 (4): 341-50.

Camerer, Colin, Samuel Issacharoff, George Loewenstein, Ted O'Donoghue, and Matthew Rabin. 2003. "Regulation for Conservatives: Behavioral Economics and the Case for 'Asymmetric Paternalism'." University of Pennsylvania Law Review 151: 1211-54.

Camerer, Colin F., George Loewenstein, and Matthew Rabin, eds. 2003. Advances in Behavioral Economics. Princeton, NJ: Princeton University Press.

Caplan, Bryan. 2007. The Myth of the Rational Voter: Why Democracies Choose Bad Policies. Princeton, NJ: Princeton University Press. 
Chapman, Gretchen B. 1996. "Temporal Discounting and Utility for Health and Money." Journal of Experimental Psychology 22 (3): 771-91.

Chesson, Harrell, and W. Kip Viscusi. 2000. "The Heterogeneity of Time-risk Tradeoffs.” Journal of Behavioral Decision Making 13: 251-58.

Cukierman, Alex, and Allan H. Meltzer. 1989. "A Political Theory of Government Debt and Deficits in a Neo-Ricardian Framework." American Economic Review 79 (4): 713-32.

Erikson, Robert S. 2013. "Policy Responsiveness to Public Opinion." Oxford Bibliographies. http:// www.oxfordbibliographies.com/view/document/obo-9780199756223/obo-9780199756223-0103. xml (accessed January 22, 2015).

-Feldstein, Martin S. 1964. "The Social Time Preference Discount Rate in Cost Benefit Analysis." Economic Journal 74 (294): 360-79.

Frederick, Shane, George Loewenstein, and Ted O'Donoghue. 2002. "Time Discounting and Time Preference: A Critical Review.” Journal of Economic Literature 40 (2): 351-401.

Fujii, Tomoki, and Larry Karp. 2008. "Numerical Analysis of Non-Constant Pure Rate of Time Preference: A Model of Climate Policy.” Journal of Environmental Economics and Management 56 (1): 83-101.

Glaeser, Edward L. 2006. "Paternalism and Psychology.” University of Chicago Law Review 73 (1): 133-56.

Gottlieb, Daniel. 2008. “Competition over Time-Inconsistent Consumers.” Journal of Public Economic Theory 10 (4): 673-84.

Goulder, Lawrence H., and Roberton C. Williams. 2012. "The Choice Of Discount Rate For Climate Change Policy Evaluation." Climate Change Economics 3 (4).

-Gul, Faruk, and Wolfgang Pesendorfer. 2001. "Temptation and Self-Control." Econometrica 69 (6): 1403-35.

Gul, Faruk, and Wolfgang Pesendorfer. 2004. "Self-Control and the Theory of Consumption." Econometrica 72 (1): 119-58.

Halac, Marina, and Pierre Yared. 2014. "Fiscal Rules and Discretion under Persistent Shocks." Econometrica 82 (5): 1557-1614.

Heidhues, Paul, and Botond Köszegi. 2010. "Exploiting Naïvete about Self-Control in the Credit Market." American Economic Review 100 (5): 2279-2303.

Hurst, Erik. 2003. "Grasshoppers, Ants, and Pre-Retirement Wealth: A Test of Permanent Income." National Bureau of Economic Research Working Paper 10098.

Hwang, Jisoo, and Johanna Mollerstrom. 2012. "Political Reform with Time-Inconsistent Voters." Unpublished.

Jackson, Matthew O., and Leeat Yariv. Forthcoming. "Collective Dynamic Choice: The Necessity of Time Inconsistency.” American Economic Journal: Microeconomics.

- Johannesson, Magnus, and Per-Olov Johansson. 1996. "The Discounting of Lives Saved in Future Generations-Some Empirical Results." Health Economics 5 (4): 329-32.

Karp, Larry. 2005. "Global warming and hyperbolic discounting." Journal of Public Economics 89 (2-3): 261-82.

Karp, Larry, and Yacov Tsur. 2011. "Time Perspective and Climate Change Policy." Journal of Environmental Economics and Management 62 (1): 1-14.

Krusell, Per, Burhanettin Kurusçu, and Anthony A. Smith Jr. 2002. "Equilibrium Welfare and Government Policy with Quasi-geometric Discounting." Journal of Economic Theory 105 (1): 42-72.

Krusell, Per, Burhanettin Kurusçu, and Anthony A. Smith. 2010. “Temptation and Taxation.” Econometrica 78 (6): 2063-84.

-Laibson, David. 1997. "Golden Eggs and Hyperbolic Discounting." Quarterly Journal of Economics $112(2): 443-78$.

-Laibson, David. 1998. "Life-Cycle Consumption and Hyperbolic Discount Functions.” European Economic Review 42 (3-5): 861-71.

Laibson, David I., Andrea Repetto, and Jeremy Tobacman. 2007. "Estimating Discount Functions with Consumption Choices over the Lifecycle." National Bureau of Economic Research Working Paper 13314.

Lizzeri, Alessandro. 1999. "Budget Deficits and Redistributive Politics." Review of Economic Studies 66 (4): 909-28.

Lizzeri, Alessandro, and Leeat Yariv. 2014. "Collective Self-Control.” Unpublished.

Madrian, Brigitte C. 2012. "Matching Contributions and Savings Outcomes: A Behavioral Economics Perspective.” National Bureau of Economic Research Working Paper 18220.

-Marglin, Stephen A. 1963. "The Social Rate of Discount and The Optimal Rate of Investment." Quarterly Journal of Economics 77 (1): 95-111. 
Mastrandrea, Michael. D., and Stephen H. Schneider. 2010. Preparing for Climate Change. Cambridge, MA: MIT Press.

Nordhaus, William. 2009. "Measuring Real Income with Leisure and Household Production.” In Measuring the Subjective Well-Being of Nations: National Accounts of Time Use and Well-Being, edited by Alan B. Krueger, 125-44. Chicago: Chicago University Press.

Nordhaus, William D., and Joseph Boyer. 2003. Warming the World: Economic Models of Global Warming. Cambridge, MA: MIT Press.

O'Donoghue, Ted, and Matthew Rabin. 1999. "Doing It Now or Later." American Economic Review 89 (1): 103-24.

Ortoleva, Pietro, and Erik Snowberg. 2015. "Overconfidence in Political Behavior." American Economic Review 105 (2): 504-35.

Persson, Torsten, and Lars E. O. Svensson. 1989. "Why a Stubborn Conservative Would Run a Deficit: Policy with Time Inconsistent Preferences." Quarterly Journal of Economics 104 (2): 325-45.

Persson, Torsten, and Guido Tabellini. 1990. Macroeconomic Policy, Credibility and Politics. New York: Harwood Academic Publishers.

Piguillem, Facundo, and Alessandro Riboni. 2013. "Political Turnover, Dynamic Separation of Power and Efficiency." Unpublished.

Rizzo, Mario J., and Douglas Glen Whitman. 2009a. "The Knowledge Problem of the New Paternalism.” Brigham Young University Law Review 2009 (4): 103-61.

Rizzo, Mario J., and Douglas Glen Whitman. 2009b. "Little Brother Is Watching You: New Paternalism on the Slippery Slopes." Arizona Law Review 51 (3): 685-739.

- Rowse, John. 2006. "On Hyperbolic Time Discounting in Exhaustible Resource Models: An Application to World Oil Resources." Natural Resource Modeling 19 (2): 243-77.

Settle, Chad, and Jason F. Shogren. 2006. "Does Integrating Economic and Biological Systems Matter for Public Policy? The Case of Yellowstone Lake." B. E. Journal of Economic Analysis \& Policy 6 (1).

Shui, Haiyan, and Lawrence M. Ausubel. 2005. "Time Inconsistency in the Credit Card Market." Unpublished.

-Song, Zheng, Kjetil Storesletten, and Fabrizio Zilibotti. 2012. "Rotten Parents and Disciplined Children: A Politico-Economic Theory of Public Expenditure and Debt." Econometrica 80 (6): 2785-2803.

-Sozou, Peter D. 1998. "Hyperbolic Discounting and Uncertain Hazard Rates." Proceedings of the Royal Society B 265 (1409): 2015-2020.

Sunstein, Cass R. 2006. "Boundedly Rational Borrowing." University of Chicago Law Review 73 (1): 249-70.

Tabellini, Guido. 1991. "The Politics of Intergenerational Redistribution.” Journal of Political Economy 99 (2): 335-57.

Thaler, Richard H., Cass R. Sunstein. 2003. "Libertarian Paternalism." American Economic Review 93 (2): 175-79.

Thaler, Richard H., and Cass R. Sunstein. 2009. Nudge: Improving Decisions About Health, Wealth, and Happiness. London: Penguin.

van der Pol, Marjon, and John A. Cairns. 2001. "Estimating Time Preferences for Health Using Discrete Choice Experiments.” Social Science and Medicine 52 (9): 1459-70.

van der Pol, Marjon, and John A. Cairns. 2002. "A Comparison of the Discounted Utility Model and Hyperbolic Discounting Models in the Case of Social and Private Intertemporal Preferences for Health." Journal of Economic Behavior \& Organization 49 (1): 79-96.

$\checkmark$ van der Pol, Marjon, and John A. Cairns. 2011. "Descriptive Validity of Alternative Intertemporal Models for Health Outcomes: An Axiomatic Test." Health Economics 20 (7): 770-82.

Velasco, Andres. 1996. "A Model of Endogenous Fiscal Deficits and Delayed Fiscal Reforms." National Bureau of Economic Research Working Paper 6336.

Viscusi, W. Kip, and Joel Huber. 2006. "Hyperbolic Discounting of Public Goods." National Bureau of Economic Research Working Paper 11935.

-Weitzman, Martin L. 2001. "Gamma Discounting.” American Economic Review 91 (1): 260-71. 